\section{Toothpaste becomes first OHF approved product for relief of tooth sensitivity and remineralisation}

BioMin F, the pioneering toothpaste which replaces lost tooth mineral, has become the first toothpaste to gain accreditation from the Oral Health Foundation's (OHF) expert panel for both sensitivity reduction and remineralisation.

Surveys indicate that more than $40 \%$ of adults experience tooth sensitivity at some stage during their lifetimes.

BioMin F toothpaste works through its slow release of calcium, phosphate and fluoride ions which form a protective fluoro apatite layer on the tooth surface. This apatite effectively seals any exposed and open dentine tubules which are a key cause of tooth sensitivity due to their direct link with the central nervous system.

BioMin Chief Executive Richard Whatley said: 'Oral Health Foundation accreditation is a hugely important endorsement of our toothpaste as it assures consumers that BioMin F has been evaluated by an independent panel of internationally recognised dental experts and academics. These experts have studied all the claims carefully to ensure they are true and are backed up by reliable scientific evidence.'

The Foundation has the biggest oral healthcare product accreditation scheme in the world and

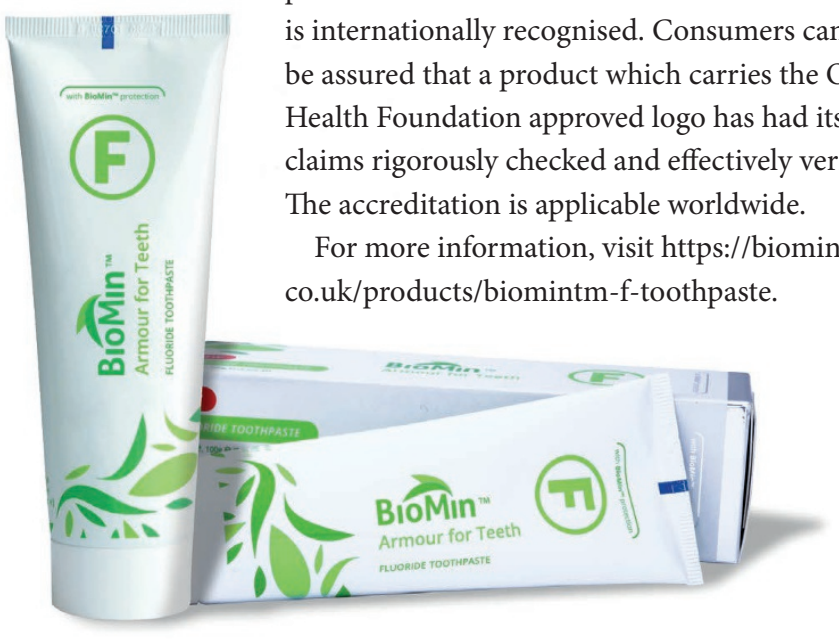

\section{Digital innovations and dental implantology}

Are you interested in how the growing reliance on digital technologies is changing the face of dental implantology?

On 2 May 2019 during the ADI Team Congress 2019 in Edinburgh, Nobel Biocare will be holding a Corporate Forum with two lectures that will explore how digital technology is transforming dental implantology.

The first lecture, hosted by Andrew Dawood, will detail how digital technology improves the implant treatment workflow from diagnosis to treatment outcome. The second will be headed by Oscar Gonzalez and will delve into the impact of immediate implant placement and how provisional restorations affect aesthetics.

This Corporate Forum is free for anybody attending the ADI Team Congress 2019 and delegates can earn 2.5 hours of CPD.

For more information, contact Nobel Biocare on 0208756 3300 , or visit www.nobelbiocare.com.

\section{Selling a practice with expert help}

Choosing who to sell a dental practice to is almost as important as how much it is sold for. After years of dedication to the business, principals want to leave knowing that the new owner has only the best intentions for the practice, patients and dental team.

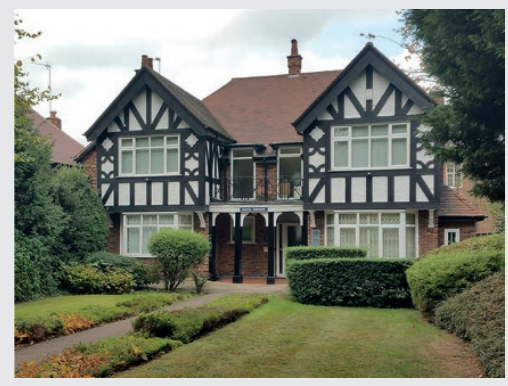

The board of directors at Rodericks Dental is mainly dentists and so they understand dentistry and its challenges. They appreciate the years of hard work put into developing and maintaining goodwill within a practice and they know what it takes to maintain and build upon this legacy.

Aside from ensuring excellent patient care, Rodericks says it is committed to its people. It continually invests in learning and career development for all members of the team, meaning that an owner can hand over the reins with peace of mind that their team and patients will be well looked after.

Because of the Rodericks team's experience in the transaction process, a sale can happen in as little as 12 weeks after signing Heads of Terms, for minimal disruption to the practice and patients. They can also offer financial support with legal costs when a recommended dental expert is used.

For more information, visit https://www.rodericksdental. co.uk/sell-your-practice/.

\section{Audit with ease}

Leading dental equipment supplier, Clark Dental, offers practitioners a quick and easy method of auditing dental radiographs with X-Ray QA software.

This innovative web-based programme is designed and developed for digitally recording radiographic quality assurance audits as part of CQC guidelines. Suited for all types of imaging systems, X-Ray QA enables practitioners to create customised audits and professional reports that can be stored online for instant accessibility.

With X-Ray QA, clinicians can compare audits side-by-side, enabling them to assess the efficacy of their radiographic equipment with ease.

More information is available by calling Clark Dental on 01268733 146, emailing info@clarkdental.co.uk or visiting www.clarkdental.co.uk.

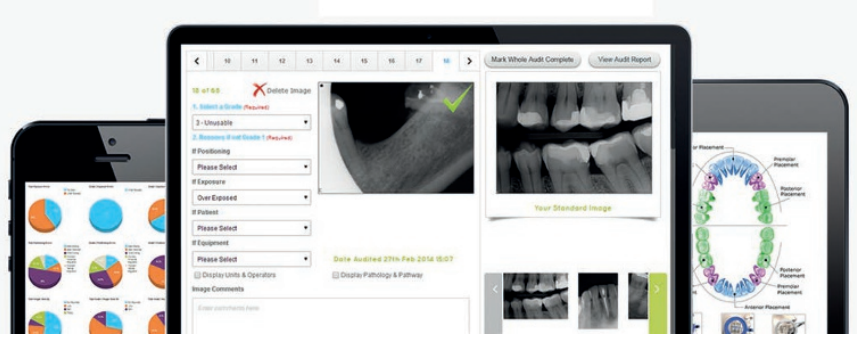

